DOI:10.17951/h.2015.49.4.35

\begin{tabular}{lcl}
\hline \multicolumn{1}{c}{ A N N A L E S } \\
UNIVERSITATIS & MARIAE CURIE-SKŁODOWSKA \\
LUBLIN - POLONIA & SECTIOH H \\
VOL. XLIX, 4 & 2015 \\
\hline
\end{tabular}

Uniwersytet Marii Curie-Skłodowskiej, Wydział Ekonomiczny

\title{
BARTŁOMIEJ BĄK
}

bakbartlomiej88@gmail.com

\section{Skuteczność techniki Ichimoku na przykładzie kontraktów terminowych na indeks WIG20}

Effectiveness of Ichimoku Technique on the Example of Index Futures on WIG20

Słowa kluczowe: technika Ichimoku Kinko Hyo, analiza techniczna

Keywords: Ichimoku Kinko Hyo technical indicator, technical analysis

Kod JEL: G10, G11, G13

\section{Wstęp}

Analiza techniczna jest przedmiotem dyskusji zarówno inwestorów, jak i środowisk akademickich. Przez część uważana jest za kompletną metodę podejmowania decyzji inwestycyjnych, inni sugerują konieczność łączenia jej z innymi metodami, jak np. analiza fundamentalna, natomiast pozostali odrzucają ją w całości. Japońskie techniki analizowania wykresów dopiero pod koniec XX w. znalazły uznanie w oczach europejskich i amerykańskich inwestorów. Dzięki publikacjom Steve'a Nisona [1991, 1996] czy Johna Murphy'ego [1999] wzrosła wiedza na temat narzędzi stosowanych w Japonii od dziesięcioleci, co z kolei przełożyło się na wzrost zainteresowania tymi zagadnieniami. Największą popularność zdobyły świece japońskie, które w porównaniu z wykresem liniowym zawierają cztery razy więcej informacji o cenach badanych aktywów, dzięki czemu w sposób bardziej kompletny odzwierciedlają sytuację rynkową. Celem niniejszego opracowania jest potwierdzenie skuteczności innej japońskiej metody analizowania wykresów - techniki Ichimoku. 


\section{Technika Ichimoku}

Technika Ichimoku Kinko Hyo, co w thumaczeniu oznacza „,wykres równowagi na pierwszy rzut oka", po raz pierwszy została przedstawiona w 1968 r. przez jej autora, Goichi Hosodę. Sama koncepcja powstała przed wybuchem II wojny światowej, jednak brak komputerów wydłużył proces opracowywania i testowania kompletnej techniki [Elliott, 2007, s. 5]. Dzieło Hosody nie zostało nigdy przetłumaczone, jednak powstały anglojęzyczne publikacje na temat tej metody, z których najobszerniejsze są autorstwa Nicole Elliott [2007] oraz Manesha Patela [2010], w której autor dodatkowo przetestował strategię opartą na Ichimoku. W Polsce tą tematyką zajmowali się przede wszystkim Kamil Oziemczuk [2011] oraz Krzysztof Borowski [2001]. W polskojęzycznych publikacjach nie pojawiły się badania skuteczności strategii oparte na prezentowanej technice.

Technika opiera się na pięciu liniach (rys. 1) zbudowanych na podstawie wykresu świecowego [Patel, 2010, s. 3-4]:

a) tenkan sen (conversion line; linia zwrotu),

b) kijun sen (base line; linia standardowa),

c) senkou span A (leading span A; pierwsza linia zakresu),

d) senkou span $B$ (leading span $B$; druga linia zakresu),

e) chikou span (lagging span; linia opóźniana).

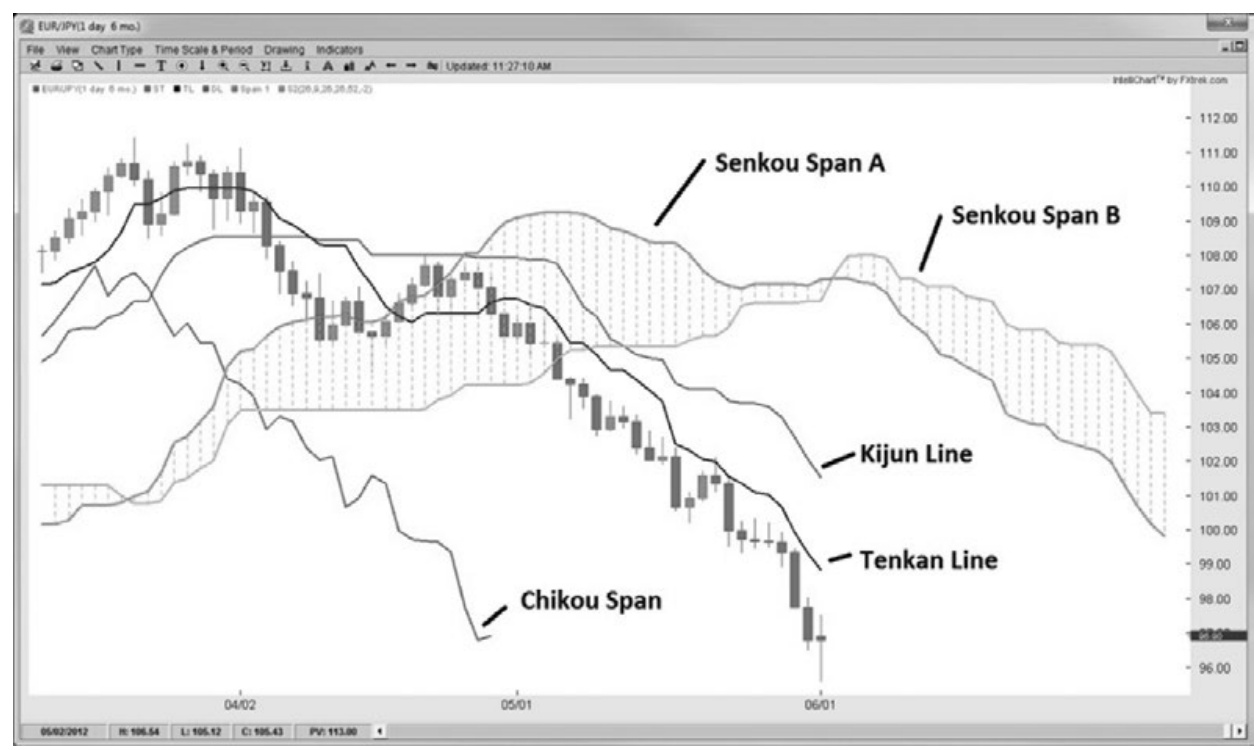

Rys. 1. Wykres z zastosowaniem techniki Ichimoku

Źródło: [http://ichimokutrading.com/ichimoku-cloud-trading-in-the-forex-market]. 
Tenkan sen jest dziewięciodniową średnią kroczącą, wykorzystującą cenę minimalną i cenę maksymalną z badanego okresu. Kijun sen zbudowana jest analogicznie, jednak przedziałem bazowym jest dla niej 26 okresów.

$$
\begin{aligned}
& \text { Tenkan } \operatorname{sen}(T)=\frac{\min _{(T-8, T)}+\max _{(T-8, T)}}{2} \\
& \text { Kijun } \operatorname{sen}(T)=\frac{\min _{(T-25, T)}+\max _{(T-25, T)}}{2} \\
& \text { gdzie: } \\
& \min _{(\mathrm{X}, \mathrm{Y})}-\text { cena minimalna w okresie od X do Y, } \\
& \max _{(\mathrm{X}, \mathrm{Y})}-\text { cena maksymalna } \mathrm{w} \text { okresie od } \mathrm{X} \text { do } \mathrm{Y} .
\end{aligned}
$$

Linia senkou span A jest średnią kroczącą wartości tenkan sen i kijun sen, przesuniętą o 26 okresów do przodu.

Senkou span $A(T+26)=\frac{\text { tenkan } \operatorname{sen}(T)+\text { kijun } \operatorname{sen}(T)}{2}$

Linia senkou span $B$ jest średnią ruchomą ceny minimalnej i ceny maksymalnej z 52 okresów, przesuniętą o 26 okresów do przodu.

Senkou span $B(T+26)=\frac{\min _{(T-51, T)}+\max _{(T-51, T)}}{2}$

Przestrzeń pomiędzy senkou span $A$ i senkou span B to humo (cloud, chmura). Ostatnia linia, chikou span, przedstawia przesuniętą o 26 okresów wstecz cenę zamknięcia [Borowski, 2001, s. 103-104].

$\operatorname{chikou} \operatorname{span}(T)=\operatorname{cena}(T+26)$

\section{Charakterystyka techniki Ichimoku}

\section{Cel badania}

Celem przeprowadzonego badania była weryfikacja hipotezy, że technika Ichimoku jest skutecznym narzędziem na polskim rynku kapitałowym oraz że na jej podstawie można tworzyć dochodowe strategie inwestycyjne. Przez skuteczność rozumie się tu osiągnięcie dodatniego wyniku w badanym okresie. W analizie wzięto pod uwagę rynek kontraktów terminowych jako najpłynniejszy, na którym można otwierać krótkie pozycje.

Badania techniki Ichimoku przeprowadzone na amerykańskim i japońskim rynku akcji [Kai Jie Shawn, Yanyali, Savidge, 2015] oraz na parach walutowych USD/ 
JPY, EUR/USD, GBP/USD, USD/CHF i AUD/USD [Shangkun, Sakurai, 2014] potwierdziły skuteczność tej techniki, zatem sprawdzenie jej skuteczności na polskim rynku jest uzasadnione.

\section{Sygnały inwestycyjne w technice Ichimoku}

Technika Ichimoku generuje szereg rodzajów sygnałów inwestycyjnych oraz określa poziomy wsparcia i oporu dla ruchów cenowych. Pierwszy z nich to przecięcie linii tenkan sen i kijun sen. Jeżeli pierwsza z nich przecina drugą od góry (przy czym za przecięcie uznaje się już moment zetknięcia linii), to jest to sygnał sprzedaży. Analogicznie sygnałem kupna jest przecięcie linii kijun sen przez tenkan sen od dołu. W zależności od umiejscowienia względem chmury można wyróżnić sygnały silne, neutralne oraz słabe. Przecięcie nad kumo oznacza słaby impuls sprzedaży i mocny - kupna. W zakresie chmury sygnały są neutralne, natomiast pod nią występuje słaby impuls kupna i silny sprzedaży.

Tab. 1. Sygnały inwestycyjne techniki Ichimoku

\begin{tabular}{|c|c|c|}
\hline Sygnał & Umiejscowienie & Znaczenie \\
\hline \multirow{3}{*}{$\begin{array}{l}\text { Kijun sen przecina od góry tenkan } \\
\text { sen lub cenę }\end{array}$} & Nad chmurą & Silny sygnał kupna \\
\hline & W chmurze & Neutralny sygnał kupna \\
\hline & Pod chmurą & Słaby sygnał kupna \\
\hline \multirow{3}{*}{$\begin{array}{l}\text { Kijun sen przecina od dołu tenkan } \\
\text { sen lub cenę }\end{array}$} & Nad chmurą & Słaby sygnał sprzedaży \\
\hline & W chmurze & Neutralny sygnał sprzedaży \\
\hline & Pod chmurą & Silny sygnał sprzedaży \\
\hline \multirow{3}{*}{ Położenie chikou span } & Nad chmurą & Silne (słabe) potwierdzenie kupna (sprzedaży) \\
\hline & W chmurze & Neutralne potwierdzenie kupna (sprzedaży) \\
\hline & Pod chmurą & Słabe (silne) potwierdzenie kupna (sprzedaży) \\
\hline Wybicie ceny nad chmurę & & Sygnał kupna \\
\hline Wybicie ceny pod chmurę & & Sygnał sprzedaży \\
\hline Chikou span przecina od góry cenę & & Sygnał sprzedaży \\
\hline Chikou span przecina od dołu cenę & & Sygnał kupna \\
\hline
\end{tabular}

Źródło: opracowanie własne.

Drugim rodzajem sygnału jest przecięcie ceny z kijun sen. Impulsem kupna jest przekroczenie przez cenę linii standardowej od dołu, natomiast sprzedaży - przecięcie od góry. Tak samo jak w poprzednim przypadku, również i w tym siła sygnału jest uzależniona od umiejscowienia względem chmury.

Kolejna wskazówka z 3-stopniowym podziałem siły to umiejscowienie chikou span względem chmury. Przeważnie jest to traktowane jako potwierdzenie innych impulsów. Gdy linia opóźniona znajduje się nad kumo, oznacza to silne potwierdzenie sygnału kupna lub słabe potwierdzenie sygnału sprzedaży. W zakresie chmury potwierdzenie jest neutralne, natomiast pod nią oznacza silne potwierdzenie sprzedaży lub słabe potwierdzenie kupna. 
Innym impulsem dla inwestorów jest wybicie ceny z chmury. Sygnał kupna generowany jest w momencie zamknięcia świecy powyżej chmury, o ile kurs wcześniej poruszał się w jej zakresie lub poniżej. Impuls sprzedaży powstaje analogicznie, gdy zamknięcie świecy znajduje się poniżej kumo.

Ostatnim sygnałem transakcyjnym jest przecięcie ceny przez chikou span. Ponieważ linia ta jest wartością ceny przesuniętą o 26 okresów, stąd można na jej podstawie określać aktualny trend rynkowy. W momencie przecięcia kursu od dołu generowany jest sygnał kupna. Przekroczenie od góry oznacza impuls do sprzedaży [Oziemczuk, 2011, s. 51-63].

\section{Strategie wykorzystane w badaniu}

W analizie skuteczności techniki Ichimoku na rynku kontraktów terminowych na WIG20 wykorzystano łącznie 24 strategie łączące sygnały kupna z metodami wyjścia z inwestycji. Strategie zostały zdefiniowane przez sygnały wejścia opisane $\mathrm{w}$ tab. 1, według przyporządkowania opisanego w tab. 2 .

Tab. 2. Sygnały zajęcia pozycji dla badanych strategii

\begin{tabular}{|l|l|c|c|c|}
\hline \multicolumn{2}{|c|}{ Sygnał } & $\begin{array}{c}\text { Brak potwierdzenia } \\
\text { chikou span/chmura }\end{array}$ & $\begin{array}{c}\text { Silne potwierdzenie } \\
\text { chikou span/chmura }\end{array}$ & $\begin{array}{c}\text { Silne lub neutralne } \\
\text { potwierdzenie chikou } \\
\text { span/chmura }\end{array}$ \\
\hline \multirow{2}{*}{$\begin{array}{l}\text { Kijun sen } \\
\text { przecina } \\
\text { tenkan sen }\end{array}$} & Silny & Strategia 1 & Strategia 9 & Strategia 17 \\
\cline { 2 - 5 } & Silny lub neutralny & Strategia 2 & Strategia 10 & Strategia 18 \\
\cline { 2 - 5 } $\begin{array}{l}\text { Kijun sen } \\
\text { przecina cenę }\end{array}$ & Sażdy & Strategia 3 & Strategia 11 & Strategia 19 \\
\cline { 2 - 5 } & Silny lub neutralny & Strategia 4 & Strategia 12 & Strategia 20 \\
\cline { 2 - 5 } & Każdy & Strategia 5 & Strategia 13 & Strategia 21 \\
\hline \multicolumn{2}{|l|}{ Cena przebija chmurę } & Strategia 7 & Strategia 14 & Strategia 22 \\
\hline \multicolumn{2}{|l|}{ Chikou span przecina cenę } & Strategia 8 & Strategia 16 & Strategia 23 \\
\hline
\end{tabular}

Źródło: opracowanie własne.

Sygnał transakcyjny powstawał w punkcie zamknięcia świecy sygnalnej. Otwarcie pozycji jest w tym momencie możliwe, gdyż na interwale dziennym jest to kurs dogrywki. Impulsem do odwrócenia transakcji było wystąpienie sygnału przeciwstawnego o takim samym charakterze, np. dla przebicia chmury przez cenę było to przebicie w przeciwnym kierunku. W związku $\mathrm{z}$ takim określeniem warunków wejścia inwestor, począwszy od wystąpienia pierwszego sygnału, przez cały czas pozostawał na rynku. W strategiach ignorowane były powtarzające się po sobie impulsy kupna lub sprzedaży - realizowany był jedynie pierwszy z nich. Niezamknięte pozycje zostały rozliczone po kursie zamknięcia $\mathrm{z}$ ostatniego dnia obserwacji.

Sygnał przecięcia kijun sen i tenkan sen został zdefiniowany jako sytuacja, w której linie przetną się lub zetkną, o ile nie pokrywały się dla poprzedzającego okresu. Ograniczenie to zabezpiecza strategię na wypadek generowania sygnałów przez 
długotrwałe pokrywanie się linii kijun sen i tenkan sen. Sygnał przecięcia kijun sen przez cenę został określony dla sytuacji, w której korpusy dwóch kolejnych świec znajdowały się po jednej stronie kijun sen (przy czym mogły się z nią stykać), a zamknięcie trzeciej świecy znalazło się po drugiej stronie linii standardowej. Wybicie ceny z chmury zdefiniowane zostało jako zamknięcie świecy nad (pod) chmurą, o ile korpusy dwóch poprzedzających świec nie znajdowały się powyżej (poniżej) jej górnej (dolnej) krawędzi. Przecięcie chikou span z ceną zostało określone analogicznie jak w przypadku przecięcia kijun sen i ceny.

Operacje zostały zasymulowane na syntetycznym instrumencie FW20 dla okresu od 3 stycznia 2000 r. (pierwsza sesja w roku uruchomienia systemu WARSET) do 30 kwietnia 2015 r. (dzień przeprowadzenia badania), na interwale dziennym. Syntetyczny FW20 przedstawia wartości kontraktu terminowego na WIG20 dla serii o najwyższym wolumenie obrotu, dzięki czemu pomijana jest konieczność rolowania pozycji w dniu wygaśnięcia danej serii kontraktów. Derywat oparty na indeksie WIG20 jest najpłynniejszym instrumentem notowanym na warszawskim parkiecie, stąd jego wykorzystanie w badaniu. Aby pominąc kwestie związane z zarządzaniem wielkością pozycji, przyjęto, że wolumen każdej transakcji to jeden kontrakt, a inwestor zawsze ma środki na jego zakup. Wyniki uzyskane dla poszczególnych strategii zostały określone w punktach dla uzyskania lepszej porównywalności. Do dnia 23 września 2013 r. wartość jednego punktu dla wszystkich serii kontraktów wynosiła $10 \mathrm{zł}$, natomiast po tej dacie dla każdej nowej serii wynosiła $20 \mathrm{zł}$. Wyniki strategii generujących więcej sygnałów po zmianie wartości mnożnika kontraktu byłyby przeszacowane względem pozostałych, dlatego zrezygnowano z podania wyniku wyrażonego w jednostkach pieniężnych. Do obliczenia wyników strategii wykorzystano arkusz kalkulacyjny Microsoft Excel oraz dane z serwisu www.bossa.pl.

Dla uproszczenia pominięto kwestie podatkowe, prowizje maklerskie oraz operacje marking to market, a także przyjęto nieograniczoną płynność transakcji.

\section{Badanie empiryczne}

\section{Wyniki badania}

Spośród 24 analizowanych strategii 22 okazały się zyskowne, natomiast dwie przyniosły stratę. Niekorzystne okazało się wykorzystanie sygnałów przecięcia kijun sen i ceny w wersji mocnej i neutralnej oraz mocnej, neutralnej i słabej, w przypadku gdy nie korzystano z potwierdzenia sygnału przez położenie chikou span względem chmury. Szczegółowe wyniki badanych strategii zostały umieszczone w tab. 3 .

Najwyższy zysk przyniosła strategia 23, dla której wyniósł on 3290 punktów. Najwyższa strata wyniosła 1481 punktów dla strategii 6 . Najwyższy poziom skumulowanego zysku osiągnęła strategia 19 (4237 punktów), natomiast najwyższy poziom straty uzyskała strategia 6 (1908 punktów). 
Warto odnotować, że zastosowanie siedmiu z wymienionych strategii przez cały okres trwania inwestycji nie zeszło poniżej wartości początkowej, a zatem wszystkie poniesione straty pomniejszały zyski, a nie zainwestowany kapitał.

Tab. 3. Wyniki badanych strategii inwestycyjnych (w punktach)

\begin{tabular}{|c|c|c|c|c|}
\hline Strategia & Wynik końcowy & Najniższy wynik $^{1}$ & Najwyższy wynik $^{2}$ & Zysk/ryzyko \\
\hline 1 & 725 & -61 & 2094 & 11,89 \\
\hline 2 & 3005 & 0 & 3214 & - \\
\hline 3 & 503 & -141 & 1498 & 3,57 \\
\hline 4 & 2460 & -698 & 2825 & 3,52 \\
\hline 5 & -1218 & -1393 & 894 & Brak zysku \\
\hline 6 & -1481 & -1908 & 300 & Brak zysku \\
\hline 7 & 1921 & -233 & 3004 & 8,24 \\
\hline 8 & 221 & -1043 & 474 & 0,21 \\
\hline 9 & 1689 & -591 & 2281 & 2,86 \\
\hline 10 & 3179 & 0 & 3881 & - \\
\hline 11 & 3179 & 0 & 3881 & - \\
\hline 12 & 2460 & -698 & 2825 & 3,52 \\
\hline 13 & 2330 & -230 & 3293 & 10,13 \\
\hline 14 & 2280 & -280 & 3243 & 8,14 \\
\hline 15 & 2440 & 0 & 3891 & - \\
\hline 16 & 2305 & -53 & 3896 & 43,49 \\
\hline 17 & 725 & -61 & 2094 & 11,89 \\
\hline 18 & 2743 & 0 & 3513 & - \\
\hline 19 & 3143 & 0 & 4237 & - \\
\hline 20 & 2460 & -698 & 2825 & 3,52 \\
\hline 21 & 3218 & 0 & 3847 & - \\
\hline 22 & 2980 & -52 & 3453 & 57,31 \\
\hline 23 & 3290 & -118 & 4158 & 27,88 \\
\hline 24 & 3059 & -953 & 3434 & 3,21 \\
\hline średnia & 1984 & -384 & 2877 & 5,17 \\
\hline
\end{tabular}

Źródło: opracowanie własne.

Ryzyko związane z inwestycją zostało przedstawione jako relacja zysku końcowego do najniższego zrealizowanego wyniku punktowego w czasie przebiegu badania. Oznacza to, że dla inwestora korzystna jest jak najwyższa wartość tego wskaźnika. Najwyższy poziom wyniósł 57,31 dla strategii 22 , a więc osiągnięty zysk był ponad 57-krotnie wyższy niż najwyższa osiągnięta w tej strategii strata. Dla dziewięciu strategii, w których nie poniesiono straty lub nie osiągnięto dodatniego wyniku końcowego, wartość wskaźnika nie została określona. Warto podkreślić, że tak określone ryzyko nie uwzględnia potencjalnych strat wynikających z niezrealizowanych transakcji.

\footnotetext{
1 Najniższy skumulowany wynik zysków i strat osiągnięty w trakcie trwania badania.

2 Najwyższy skumulowany wynik zysków i strat osiągnięty w trakcie trwania badania.

3 Relacja osiągniętego zysku do maksymalnego obsunięcia kapitału względem wartości początkowej w analizowanej strategii.
} 


\section{Wnioski}

W przeprowadzonym badaniu ponad $90 \%$ strategii opartych na technice Ichimoku przyniosło ponadprzeciętne zyski. Uzyskano średni wynik na poziomie 1984 punktów, co oznacza osiągnięcie w badanym okresie ponad 2640 zł zysku rocznie na jednym kontrakcie (przy założeniu, że wartość jednego punktu kontraktowego wynosi $20 \mathrm{zł}$ ). Na tej podstawie można stwierdzić, że metoda ta umożliwia stworzenie zyskownej strategii inwestycyjnej, a jej założenia sprawdzają się również na polskim rynku.

\section{Dyskusja}

Zastosowanie opisanych $\mathrm{w}$ badaniu strategii $\mathrm{w}$ warunkach rzeczywistych wiązałoby się z wystawieniem inwestora na duże ryzyko związane ze zmianą wartości kontraktu terminowego. Brak zleceń zabezpieczających w powiązaniu z pominiętymi powyżej operacjami marking to market zmuszałby inwestora do posiadania odpowiednio wysokich środków zapewniających utrzymanie pozycji. Najwyższa odnotowana skumulowana strata wyniosła 1908 punktów, co przy obecnej specyfikacji kontraktu terminowego na indeks WIG20 oznacza 38160 zł straty. Należałoby również przeanalizować skuteczność strategii opartych na technice Ichimoku na innych instrumentach finansowych notowanych na polskim rynku kapitałowym. Do zbadania pozostaje wykorzystanie sygnałów generowanych przez technikę Ichimoku na innych interwałach czasowych oraz w połączeniu z innymi metodami analizy technicznej. W procesie inwestycyjnym konieczne jest również uwzględnienie kosztów transakcyjnych i podatkowych.

\section{Zakończenie}

Technika Ichimoku generuje sygnały oparte na podstawie aktualnych i przeszłych poziomów cenowych, dzięki czemu umożliwia identyfikację trendu oraz ułatwia predykcje ruchów kursu.

Celem artykułu było przeanalizowanie skuteczności japońskiej metody na polskimrynku kapitałowym. Do badania wykorzystano kontraktterminowy na główny indeks rynku warszawskiego - WIG20 i posłużono się dziennym interwałem transakcji na przestrzeni ostatnich 15 lat. Wyniki podobnych badań, przeprowadzonych na amerykańskim i japońskim rynku akcji oraz na parach walutowych USD/JPY, EUR/USD, GBP/USD, USD/CHF i AUD/USD, stanowiły podstawę do postawienia hipotezy, że strategie oparte na technice Ichimoku mogą być skuteczne również na rynku polskim.

Użycie 24 strategii w latach 2000-2015 przyniosło uśredniony zysk w wysokości 1984 punktów, podczas gdy w tym samym czasie wartość indeksu wzrosła o 63 
punkty. Wyniki badania potwierdziły postawioną hipotezę, że technika Ichimoku może być skutecznym narzędziem w podejmowaniu decyzji inwestycyjnych i na jej podstawie można stworzyć dochodową strategię inwestycyjną.

\section{Bibliografia}

Borowski K., Technika Ichimoku (renesans japońskiej techniki inwestowania), Oficyna Wydawnicza Szkoły Głównej Handlowej, Warszawa 2001.

Elliott N., Ichimoku Charts: an Introduction to Ichimoku Kinko Clouds, Harriman House Ltd., London 2007.

Kai Jie Shawn L., Yanyali S., Savidge J., Do Ichimoku Cloud Charts Work and Do They Work Better in Japan?, "International Federation of Technical Analysts Journal” 2016 [http://ieeexplore.iee.org/xpl/ login.jsp?reload=true \&tp=\&arnumber $=6948127 \&$ url=http $\% 3 \mathrm{~A} \% 2 \mathrm{~F} \% 2 \mathrm{Fieeexplore.iee..org} \% 2 \mathrm{Fx}-$ pls\%2Fabs all.jsp\%3Farnumber\%3D6948127, data dostępu: 09.10.2015].

Murphy J.J., Analiza techniczna rynków finansowych, WIG PRESS, Warszawa 1999.

Nison S., Japanese Candelstick Charting Techniques, New York Institute of Finance, New York 1991.

Nison S., Świece i inne japońskie techniki analizowania wykresów, WIG PRESS, Warszawa 1996.

Oziemczuk K., Ichimoku - japońska strategia inwestycyjna, Bullet Books, Warszawa 2011.

Patel M., Trading with Ichimoku Clouds: The Essential Guide to Ichimoku Kinko Hyo Technical Analysis, John Wiley \& Sons Inc., New York 2010.

Shangkun D., Sakurai A., Short-Term Foreign Exchange Rate Trading Based on the Support/Resistance Level of Ichimoku Kinkohyo, Information Science, Electronics and Electrical Engineering (ISEEE), 2014 International Conference, http://papers.ssrn.com/sol3/papers.cfm?abstract_id=2628581\&download=yes [data dostępu: 09.10.2015].

www.ichimokutrading.com [data dostępu: 09.10.2015].

\section{Effectiveness of Ichimoku Technique on the Example of Index Futures on WIG20}

Japan is one of the cradles of technical analysis. Methods developed there over the centuries are increasingly being used in other parts of the world, including Polish market. One of them is the Ichimoku technique that enables a quick and simple analysis of the market situation based on past price levels. The purpose of this article is to analyze the effectiveness of the investment signals generated by this method on example of WIG20 futures market.

\section{Skuteczność techniki Ichimoku na przykładzie kontraktów terminowych na indeks WIG20}

Japonia jest jedną z kolebek analizy technicznej. Metody tworzone tam na przestrzeni wieków są coraz częściej stosowane w innych częściach świata, w tym na rynku polskim. Jedną z nich jest technika Ichimoku, umożliwiająca szybką analizę sytuacji rynkowej w oparciu o przeszłe poziomy cenowe. Celem niniejszego artykułu jest przeanalizowanie skuteczności sygnałów inwestycyjnych, generowanych przez tę metodę, na przykładzie rynku kontraktów terminowych na WIG20. 